\title{
Cadmium depletes cellular iron availability through enhancing ferroportin translation via iron responsive element
}

\author{
LI SUN ${ }^{1,2}$, LIXIN WANG ${ }^{1,3}$, ZHE WANG $^{1,4}$, WEI HE $^{1}$, SHUPING ZHANG $^{1}$, \\ WENLI GUO ${ }^{1}$, YI QIAN ${ }^{1}$, HONG JI ${ }^{2}$, HAIQIN RONG ${ }^{2}$ and SIJIN LIU ${ }^{1}$ \\ ${ }^{1}$ State Key Laboratory of Environmental Chemistry and Ecotoxicology, Research Center for Eco-Environmental Sciences, \\ Chinese Academy of Sciences, Beijing 100085; ${ }^{2}$ Shandong Institute of Endocrine and Metabolic Diseases, \\ Shandong Academy of Medical Sciences, Jinan, Shandong 250062; \\ ${ }^{3}$ Department of Environmental Science and Engineering, Hebei University of Science and Technology, \\ Shijiazhuang, Hebei 050018, P.R. China; ${ }^{4}$ Department of Integrative Physiology and Pathobiology, \\ Tufts University School of Medicine, Boston, MA 02111, USA
}

Received February 6, 2014; Accepted November 3, 2014

DOI: $10.3892 / \mathrm{mmr} .2014 .3015$

\begin{abstract}
Cadmium (Cd) is a heavy metal that has detrimental effects on various organs. The widespread contamination of $\mathrm{Cd}$ in the environment, crops and food sources poses a severe threat to human health. Acute toxicities of $\mathrm{Cd}$ have been extensively investigated; however, the health impact of chronic low-dose exposure to $\mathrm{Cd}$, particularly exposure under non-toxic concentrations, has yet to be elucidated. Furthermore, the toxic threshold of $\mathrm{Cd}$ is currently unknown. Ferroportin is the only known iron exporter in vertebrate cells, and it has an essential role in controlling iron egress from cells. To the best of our knowledge, the present study is the first to verify the regulation of ferroportin by $\mathrm{Cd}$. Treatment with low-dose $\mathrm{Cd}$ (i.e. at sublethal concentrations, without undermining cell viability) increased the protein expression of ferroportin in macrophages, and this was associated with depleted cellular iron levels. Mechanistic investigations revealed that $\mathrm{Cd}$ modulated the ferroportin concentration at the translational level, via the iron responsive element located at the 5'-untranslated region of ferroportin. In conclusion, these data provide evidence for the molecular basis by which $\mathrm{Cd}$ alters cellular iron availability through elevating concentrations of ferroportin.
\end{abstract}

Correspondence to: Professor Sijin Liu, State Key Laboratory of Environmental Chemistry and Ecotoxicology, Research Center for Eco-Environmental Sciences, Chinese Academy of Sciences, 18 Shuangqing Road, Haidian, Beijing 100085, P.R. China E-mail: sjliu@rcees.ac.cn

Dr Haiqin Rong, Shandong Institute of Endocrine and Metabolic Diseases, Shandong Academy of Medical Sciences, 18877 Jing Shi Lu Road, Jinan, Shandong 250062, P.R. China

E-mail: haiqinrong@126.com

Key words: cadmium, ferroportin, iron responsive element, iron availability

\section{Introduction}

Due to a wide range of industrial applications, cadmium $(\mathrm{Cd})$ is substantially distributed in various environments (1). Absorption of $\mathrm{Cd}$ can be achieved through numerous routes, including ingestion, smoking and inhalation of polluted air, and $\mathrm{Cd}$ may accumulate in the liver, kidney, lung and heart for 20-30 years (2). Cd exposure is associated with various diseases, such as renal failure, anemia, itai-itai disease and cancer (3-5), and has therefore long been considered a threat to human health $(6,7)$. Cd elicits toxicity through various pathways, including oxidative stress and initiation of apoptosis $(8,9)$. Numerous studies have documented the cytotoxicity of $\mathrm{Cd}$ under various settings. However, there has thus far been no research that has evaluated the biological effects of $\mathrm{Cd}$ at non-toxic concentrations, such as chronic low-dose environmental exposure, which is likely coupled to cellular dysfunction and even morbidity. As a divalent metal ion, cellular intrusion of $\mathrm{Cd}$ has been suspected to result in systemic disorder of iron homeostasis; however, the mechanisms underlying $\mathrm{Cd}$-induced effects on iron metabolism remain unclear.

Iron is a necessary metal for all cells, and a fine-tuned regulatory system has evolved to maintain an elaborate balance for systemic iron homeostasis (10). The hepcidin-ferroportin axis has a central role in regulating iron flow (11). Hepcidin binds and induces degradation of its receptor ferroportin, the iron exporter, which leads to intracellular iron retention (12). Ferroportin is the only known iron exporter in mammals, which is mainly expressed in enterocytes and macrophages, and its concentration in splenic macrophages has been shown to determine the iron levels in serum and other organs $(11,12)$. Ferroportin concentration is largely regulated at the post-transcriptional level, through the iron responsive element and iron regulatory protein (IRE-IRP) regulatory system (13-15); however, it may also be regulated at the transcriptional level $(16,17)$. Ferroportin mutations or dysfunction results in iron metabolism disorders, known as ferroportin diseases, which are often associated with iron overload $(18,19)$. Type B ferroportin disease is 
characterized by increased concentrations of ferroportin, due to failure to respond to hepcidin, which causes continuous iron export from the cells into the plasma; this is associated with hyperferritinemia and excess iron in hepatocytes (20). The aim of the present study was to elucidate the regulation of ferroportin in macrophages by $\mathrm{Cd}$ at non-toxic concentrations.

\section{Materials and methods}

Cell culture. The THP-1 human macrophage, J774A.1 mouse macrophage and HEK293T human embryonic kidney cell lines were purchased from the Shanghai Cell Bank of Type Culture Collection (Shanghai, China). The cells were cultured in RPMI-1640 medium (Gibco Life Technologies, Carlsbad, CA, USA) supplemented with $10 \%$ fetal bovine serum (Hyclone Laboratories, Inc., Logan, UT, USA) and $100 \mathrm{U} / \mathrm{ml}$ penicillin/streptomycin (Hyclone Laboratories, Inc.). Activation of the THP-1 cells was initiated in complete medium with $1 \mu \mathrm{g} / \mathrm{ml}$ PMA (Promega Corporation, Madison, WI, USA) for $18 \mathrm{~h}(21)$.

AlamarBlue $^{\circledR}$ assay. Cell viability was measured using the alamarBlue assay, according to the manufacturer's instructions (Invitrogen Life Technologies, Carlsbad, CA, USA). Briefly, the THP-1 and J774A.1 cells were plated in 96-well plates, at a concentration of $5.0 \times 10^{3}$ cells/well. The cells were then treated with various concentrations of $\mathrm{CdCl}_{2}(0-64 \mu \mathrm{M}$; Sigma-Aldrich, St. Louis, MO, USA) for $24 \mathrm{~h}$, followed by reading with a microplate reader (Thermo Electron Corporation, Waltham, MA, USA) at $590 \mathrm{~nm}$ with excitation at $530 \mathrm{~nm}$.

Western blot analysis. The THP-1 cells were collected after washing with cold phosphate-buffered saline (PBS; Solarbio Science \& Technology Co., Ltd., Beijing, China), and total proteins were extracted using lysis buffer (Solarbio Science \& Technology Co., Ltd., Beijing, China) that was pre-mixed with a protease inhibitor cocktail (Roche Diagnostics, Basel, Switzerland). Protein lysates (30-50 $\mu \mathrm{g}$ total proteins) were then separated by $10 \%$ SDS-PAGE and further analyzed by western blotting, as previously described (22). Briefly, proteins were transferred onto pure nitrocellulose membranes, followed by primary antibody (in $1 \%$ milk) incubation overnight at $4^{\circ} \mathrm{C}$. The primary antibodies used in the present study were as follows: Anti-GAPDH (1:1,000; Santa Cruz Biotechnology, Inc., Dallas, TX, USA) and anti-ferroportin (1:500; Sigma-Aldrich). Subsequently, the secondary antibodies (in $1 \%$ milk) were applied for detection of the target proteins (for $1 \mathrm{~h}$ at $37^{\circ} \mathrm{C}$ ). The secondary antibodies used in the present study were as follows: Goat anti-rabbit-HRP (for GAPDH; 1:10,000; ComWin Biotech Co., Ltd., Beijing, China) and goat anti-rat-HRP (for FPN; 1:5,000; ComWin Biotech Co., Ltd.). Bands were analyzed by Image J software (version 1.48; National Institutes of Health, Bethesda, MD, USA) following coloration. GAPDH was used as an internal control.

For the inhibition of transcription or translation, THP-1 cells were treated with $\mathrm{CdCl}_{2}$ in the presence or absence of $1 \mu \mathrm{g} / \mathrm{ml}$ actinomycin D (a transcriptional inhibitor; ComWin Biotech Co., Ltd.) or cycloheximide (an inhibitor of protein biosynthesis; ComWin Biotech Co., Ltd.) for 12 h. Subsequently, cells were cultured with new medium containing $\mathrm{CdCl}_{2}$ for another $12 \mathrm{~h}$.
$R N A$ extraction and reverse transcription-quantitative polymerase chain reaction ( $R T-q P C R)$. Following treatment with 4 and $8 \mu \mathrm{M} \mathrm{CdCl}_{2}$ for $24 \mathrm{~h}$ (where $100 \mu \mathrm{M}$ ferric ammonium citrate was used as a positive control), total RNAs were extracted from the THP-1 cells using TRIzol ${ }^{\circledR}$, according to the manufacturer's instructions (Invitrogen Life Technologies). For the reverse transcription reaction, $2 \mu \mathrm{g}$ total RNAs were used to synthesize first strand cDNA, using oligo (dT) primers. qPCR was conducted to determine gene expression levels using SYBR ${ }^{\circledR}$ Green qPCR Master mix (Qiagen, Hilden, Germany) on a Mx3005P qPCR system (Agilent Technologies, Inc., Santa Clara, CA, USA). The primer sequences used in the present study were as follows: Forward: 5'-CGGTGTCTGTGTTTCTGGTAGA-3' and reverse: 5'-CTGGGCCACTTTAAGTCTAGC-3' for Ferroportin; and forward: 5'-GAAGGTGAAGGTCGGAGT-3' and reverse: 5'-GAAGATGGTGATGGGATTTC-3' for GAPDH. GAPDH was used as a housekeeping gene for normalization. The qRT-PCR reaction was run at $95^{\circ} \mathrm{C}$ for $5 \mathrm{~min}$ (pre-denaturation) followed by 45 cycles at $95^{\circ} \mathrm{C}$ for $15 \mathrm{sec}$, at $55^{\circ} \mathrm{C}$ for $30 \mathrm{sec}$, and at $72^{\circ} \mathrm{C}$ for $30 \mathrm{sec}$. Following the reaction, a melting curve analysis from $60-95^{\circ} \mathrm{C}$ was applied to all reactions to ensure consistency and specificity of the amplified products. Bands formed during agarose gel electrophoresis were quantified using the Image J software.

Luciferase reporter assay. A DNA fragment of the IRE sequence encoding the 5'-UTR of human ferroportin mRNA was cloned and then subcloned into the 5'-UTR of the luciferase gene, within the pGL3-Promoter luciferase reporter vector (Promega Corporation). The HindIII (Invitrogen Life Technologies) and NCOI (Invitrogen Life Technologies) enzymes were used in the construction of the plasmid. The constructed plasmid was validated by DNA sequencing using RVprimer3 primer(Invitrogen Life Technologies) and sequence alignment was performed with ClustalX software (version 2.1; Conway Institute University College Dublin, Dublin, Ireland). In the transfection experiments, $0.8 \mu \mathrm{g}$ target plasmid and 80 ng Renilla luciferase plasmid were co-transfected into HEK293T cells using Lipofectamine ${ }^{\circledR} 2000$ (Invitrogen Life Technologies) in 24-well plates. Following a $24 \mathrm{~h}$ incubation, the cells were washed with cold PBS, and then subjected to luciferase activity determination, using a Dual-Luciferase Reporter Assay system (Promega Corporation). Relative firefly luciferase activities were calculated by normalization to those of Renilla luciferase.

Labile iron pool (LIP) measurement. Following treatment of THP-1 and J774A. 1 cells with $8 \mu \mathrm{M} \mathrm{CdCl}_{2}$ for $24 \mathrm{~h}$, intracellular LIP levels were evaluated according to the standard calcein acetoxymethyl ester staining method (Sigma-Aldrich), as described previously (23). Briefly, cells were washed twice with PBS and treated with $0.5 \mu \mathrm{M}$ calcein (Sigma-Aldrich) for $15 \mathrm{~min}$ at $37^{\circ} \mathrm{C}$. Subsequently, cells were washed twice with PBS and divided into two parts. An aliquot was treated with $100 \mu \mathrm{M}$ desferoxamine (Sigma-Aldrich) for $1 \mathrm{~h}$ at $37^{\circ} \mathrm{C}$ and the other was left untreated. The intracellular fluorescence was then measured by FACS analysis with excitation at $488 \mathrm{~nm}$ and reading at $525 \mathrm{~nm}$ with a flow cytometer (FACS Calibur ${ }^{\circledR}$; Becton Dickinson, Franklin Lakes, NJ, USA). The LIP levels were determined from deduction of the cellular fluorescence of 

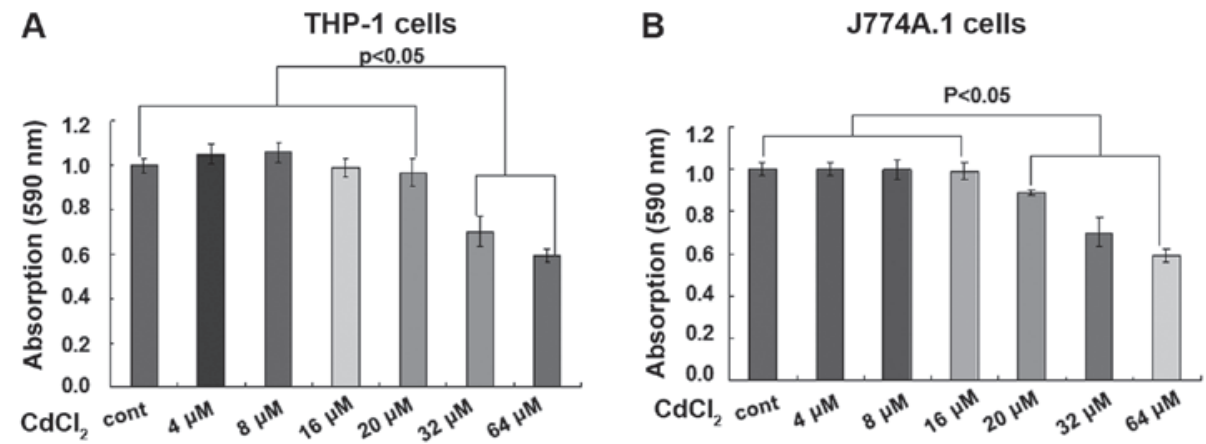

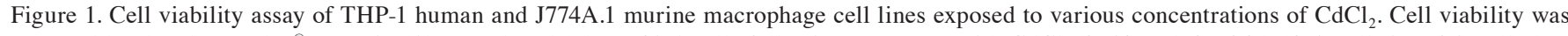
assessed by the alamarBlue ${ }^{\circledR}$ assay in (A) THP-1 and (B) J774A.1 cells following treatment with CdCl $2(0-64 \mu \mathrm{M})$ for 24 h (4-5 wells in a 96-well plate containing each concentration). The data are represented as the mean \pm standard error.

deferoxamine-treated cells, compared with the fluorescence of untreated cells.

Statistical analysis. Two-tailed Student's t-test and one-way analysis of variance were used to analyze the experimental data. The SPSS Statistics 17.0 package (SPSS, Inc., Chicago, IL, USA) was utilized to analyze the data. The data are represented as the mean \pm standard error. $\mathrm{P}<0.05$ was considered to indicate a statistically significant difference.

\section{Results and Discussion}

Ferroportin is the only known iron exporter in mammalian cells, and it is mainly expressed on macrophages and duodenal enterocytes (24-26). Macrophages have a key role in maintaining iron homeostasis, through governing iron egress into plasma $(27,28)$. The present study focused on the biological effects of $\mathrm{Cd}$ on the concentration of ferroportin in macrophages. To accurately determine the potential effects of $\mathrm{Cd}$ on ferroportin, sublethal concentrations of $\mathrm{CdCl}_{2}$ were identified that did not induce significant toxicity in macrophages, in order to determine the effects of relatively low non-toxic concentrations of $\mathrm{Cd}$. Cell viability was evaluated following treatment with various concentrations of $\mathrm{CdCl}_{2}$ in THP-1 and J774A.1 cells. Cell viability of THP-1 cells was significantly reduced in response to treatment with $\mathrm{CdCl}_{2}$ at concentrations $\geq 32 \mu \mathrm{M}$ for $24 \mathrm{~h}$, as determined by an alamarBlue assay (Fig. 1A; $\mathrm{P}<0.05$ ). The cell viability of J774A.1 cells was significantly decreased in response to treatment with $\mathrm{CdCl}_{2}$ at concentrations $\geq 20 \mu \mathrm{M}$ for $24 \mathrm{~h}$ (Fig. 1B; $\mathrm{P}<0.05$ ). Therefore, two non-toxic concentrations, 4 and $8 \mu \mathrm{M}$, were selected for use in the following experiments.

The possible influence of $\mathrm{CdCl}_{2}$ treatment was then determined on the expression of ferroportin. Since, to the best of our knowledge, only a human ferroportin antibody has been reported to function effectively, and no efficient mouse ferroportin antibody is commercially available, the protein expression of ferroportin was only examined in the THP-1 cells. Following treatment of the cells with 4 and $8 \mu \mathrm{M} \mathrm{CdCl}_{2}$ for $24 \mathrm{~h}$, the cells were collected for western blot analysis. Ferroportin protein expression was markedly increased, by $>2$-fold, in the 4 and $8 \mu \mathrm{M}$ Cd-treated cells, as compared with the untreated cells (Fig. 2A). To investigate the mechanisms responsible for the $\mathrm{Cd}$-induced increase in ferroportin protein, THP-1 cells were treated with $\mathrm{CdCl}_{2}$ in the presence or absence of $1 \mu \mathrm{g} / \mathrm{ml}$ actinomycin D

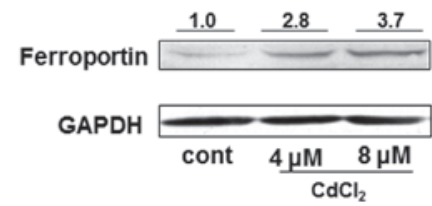

B

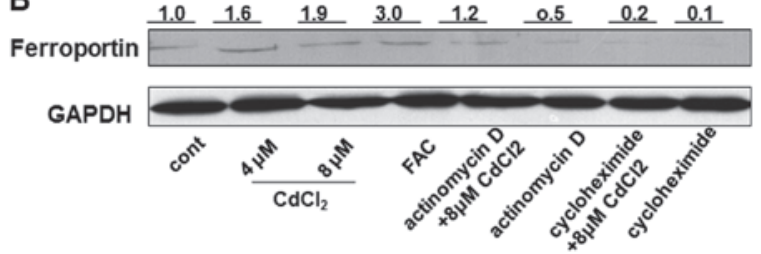

Figure 2. Ferroportin protein expression in THP-1 human macrophage cells upon treatment with $\mathrm{CdCl}_{2}$, as determined by western blotting. Cells were treated with (A) 4 or $8 \mu \mathrm{M} \mathrm{CdCl}_{2}$ for $24 \mathrm{~h}$, (B) with or without $1 \mu \mathrm{g} / \mathrm{ml}$ actinomycin D or $10 \mu \mathrm{g} / \mathrm{ml}$ cycloheximide for $12 \mathrm{~h}$. FAC, ferric ammonium citrate.

(a transcriptional inhibitor) and $10 \mu \mathrm{g} / \mathrm{ml}$ cycloheximide (an inhibitor of protein biosynthesis) for $12 \mathrm{~h}$. The protein expression of ferroportin in the cells simultaneously treated with $\mathrm{Cd}$ and actinomycin D was reduced by $\sim 40 \%$, as compared with the cells treated with $\mathrm{Cd}$ alone; however, the protein expression was still greater $(\sim 20 \%)$ in the Cd-treated cells, as compared with the untreated cells (Fig. 2B). Furthermore, the protein expression of ferroportin was markedly reduced, by $\sim 90 \%$, in the cells treated with $\mathrm{Cd}$ and cycloheximide, as compared with the cells treated with $\mathrm{Cd}$ alone (Fig. 2B). These results indicate that the regulation of ferroportin by $\mathrm{Cd}$ may occur at the transcriptional and post-translational levels, but appears more likely to occur at the post-translational level. Ferric ammonium citrate $(100 \mu \mathrm{M})$ was used as a positive control to promote ferroportin concentration (Fig. 2B). In addition, the mRNA expression levels of ferroportin were determined in the cells treated with $8 \mu \mathrm{M} \mathrm{CdCl}_{2}$ by RT-qPCR. There were no significant differences in the ferroportin mRNA expression levels between the $\mathrm{Cd}$-treated and untreated cells ( $\mathrm{P}>0.05$, data not shown). These results suggest that the regulation of ferroportin by $\mathrm{Cd}$ primarily occurs at the post-transcriptional level.

In regards to the post-transcriptional regulation of ferroportin, an IRE within its 5'-UTR has been recognized as being under the control of IRPs $(15,17)$. As a divalent metal ion, Cd possesses similar properties to iron (29), and it has long been 


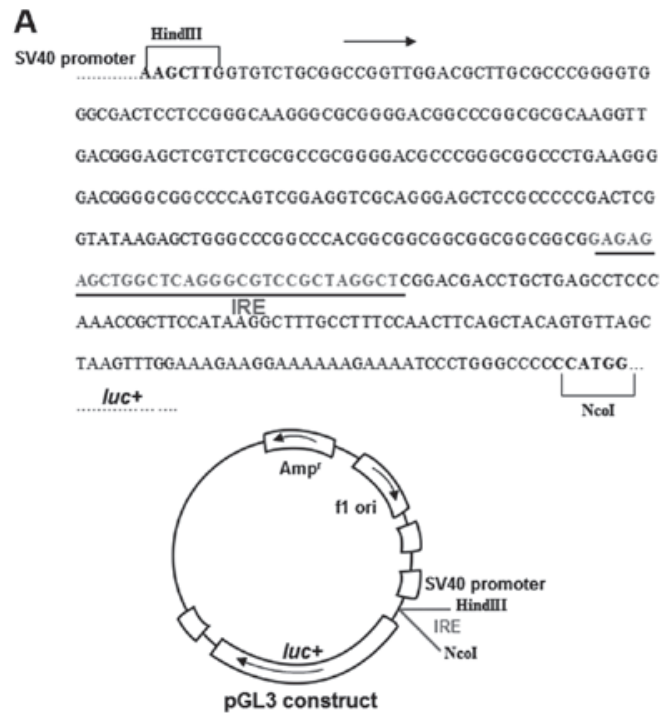

B

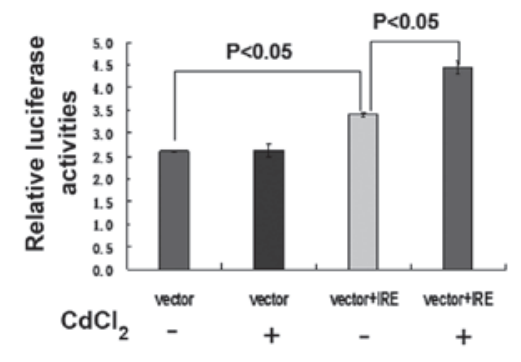

Figure 3. Effects of $\mathrm{CdCl}_{2}$ in driving the iron responsive element-iron regulatory protein (IRE-IRP) regulatory system. (A) Schematic diagram delineating the construction of the IRE-containing vector, known as vector+IRE. The IRE region was inserted into the 5'-untranslated region of the luciferase gene within a pGL3-promoter luciferase reporter vector, using restriction endonuclease, HindIII and NcoI. (B) Analysis of relative luciferase activities. pGL3-based constructs with IRE (vector+IRE) or without IRE (vector) were co-transfected with Renilla luciferase plasmid into HEK293T human embryonic kidney cells, and treated with or without $8 \mu \mathrm{M} \mathrm{CdCl}_{2}$ for $24 \mathrm{~h}$. Relative luciferase activities were normalized to those of Renilla luciferase (n=4). The data are represented as the mean \pm standard error.

A

THP-1 cells

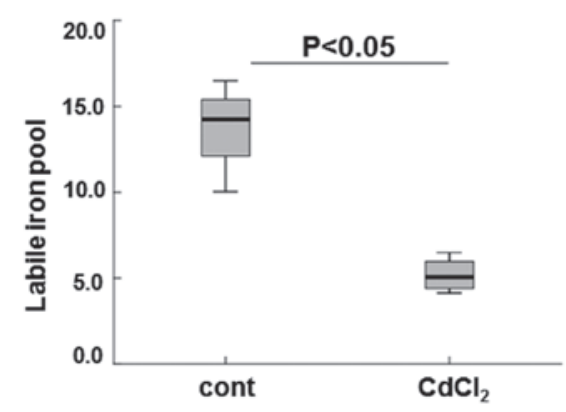

B

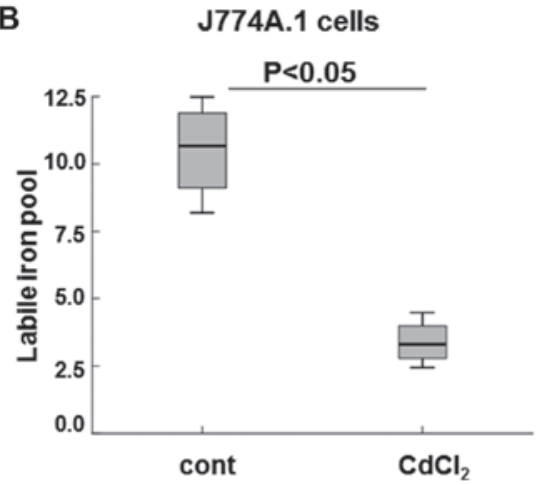

Figure 4. Relative labile iron pool (LIP) levels in THP-1 human and J774A.1 murine macrophage cells exposed to $\mathrm{CdCl}_{2}$. Calcein acetoxymethyl ester-based intracellular LIP level assay was performed in (A) THP-1 and (B) J774A.1 cells following treatment with $8 \mu \mathrm{M} \mathrm{CdCl}_{2}$ for $24 \mathrm{~h}(\mathrm{n}=4)$. Cadmium reduces intracellular iron by enforcing ferroportin translation via iron responsive element. The data are represented as the mean \pm standard error.

postulated that Cd may interfere with the transport and metabolism of numerous essential metals, including iron, copper and zinc, presumably through competition between $\mathrm{Cd}$ and the other metals $(30,31)$. Therefore, the present study investigated the possible interruption of IRP-IRE actions on the 5'-UTR of ferroportin, by $\mathrm{Cd}$. A construct was generated by inserting a fragment of the IRE DNA sequence ahead of the 5'-UTR of luciferase, within a pGL3-promoter luciferase reporter vector (Fig. 3A). Treatment with $\mathrm{CdCl}_{2}$ significantly enhanced luciferase activity by $>27 \%$ in the cells transfected with vector+IRE, as compared with the untreated cells (Fig. 3B; $\mathrm{P}<0.05$ ). Conversely, there were no significant differences in luciferase activity observed in the cells transfected with the construct devoid of IRE, with or without $\mathrm{CdCl}_{2}$ treatment (Fig. 3B). Notably, the luciferase activity of the cells transfected with vector+IRE was increased by $33 \%$, as compared with the cells transfected with vector only (Fig. 3B, $\mathrm{P}<0.05$ ), thus implying that IRE is required for maintaining ferroportin levels. These results collectively demonstrate that $\mathrm{Cd}$ regulates ferroportin protein expression predominantly through the IRE-IRP regulatory system, and $\mathrm{Cd}$ presumably replaced iron in driving IRP removal from IRE in the 5'-UTR of ferroportin.

LIP is a sensitive marker of iron storage and bioavailability, which dynamically binds to low-affinity ligands depending on different physiological settings $(32,33)$. LIP levels are concertedly regulated and maintained within a strict range that meets cellular demand for iron, but prevents excess iron-triggered damage (23). To assess the effects of Cd-induced increased ferroportin on cellular iron storage and bioavailability, LIP levels were measured in the THP-1 and J774A.1 cells treated with $8 \mu \mathrm{M} \mathrm{CdCl}_{2}$. Treatment with Cd significantly decreased LIP levels by $>3$-fold in the THP- 1 cells, as compared with the control cells (Fig. 4A; P<0.05). A similar decrease in LIP levels was observed in the J774A.1 cells treated with $\mathrm{Cd}$, as compared with the untreated cells (Fig. 4B, $\mathrm{P}<0.05$ ). These results suggest that increased LIP levels were correlated with increased ferroportin expression, in response to treatment with Cd. 
Numerous previous studies have revealed deleterious actions of $\mathrm{Cd}$ in diverse systems and models (2-5); however, relatively few studies have attempted to determine the potential biological effects of exposure to chronic sublethal $\mathrm{Cd}$ levels. Increasing evidence has suggested that $\mathrm{Cd}$ may affect the homeostasis of essential metals, through competition or other unknown mechanisms $(34,35)$. Cd burden was previously shown to stimulate the expression of divalent metal transporter 1 in enterocytes (36). Furthermore, a previous study demonstrated that $\mathrm{Cd}$ could attenuate erythropoietin production in the kidney, leading to an increase of hepcidin, which is often coupled with iron disorders (37). Park and Chung (38) also reported that $\mathrm{Cd}$ could disturb iron homeostasis by producing reactive oxygen species (38). However, research aiming to fully elucidate the effects of $\mathrm{Cd}$ on iron-associated genes and proteins remains limited, and further studies are required, in order to improve knowledge.

In conclusion, the present study identified a novel regulation of ferroportin by $\mathrm{Cd}$. Ferroportin protein expression was upregulated in response to sublethal treatment of $\mathrm{Cd}$ in macrophages, resulting in attenuation of LIP. Notably, the results suggest that Cd may regulate ferroportin translation through the 5'-UTR IRE of ferroportin. These results therefore may have identified the molecular basis by which Cd impairs cellular iron storage and bioavailability, under non-toxic concentrations in macrophages.

\section{Acknowledgements}

The present study was supported by a grant from the National '973' program (grant no. 2014CB932000) and the National Natural Science Foundation of China (grant no. 21377159). The authors of the present study would also like to thank the laboratory members for their assistance with the experiments and reagents.

\section{References}

1. Hetherington L, Brown T, Benham A, Bide T, Lusty P, Hards V, Hannis S and Idoine N (eds): World Mineral Production 2002-06. Keyworth, Nottingham, British Geological Survey 2008.

2. Satarug S, Garrett SH, Sens MA and Sens DA: Cadmium, environmental exposure, and health outcomes. Cien Saude Colet 16: 2587-2602, 2011.

3. Veljkovic AR, Nikolic RS, Kocic GM, et al: Protective effects of glutathione and lipoic acid against cadmium-induced oxidative stress in rat's kidney. Ren Fail 34: 1281-1287, 2012.

4. Bernhoft RA: Cadmium toxicity and treatment. Scientific World Journal 2013: 394652, 2013.

5. Cen YL, Tang LY, Lin Y, Su FX, Wu BH and Ren ZF: Association between urinary cadmium and clinicopathological characteristics of breast cancer. Zhonghua Zhong Liu Za Zhi 35: 632-635, 2013 (In Chinese).

6. Riederer AM, Belova A, George BJ and Anastas PT: Urinary cadmium in the 1999-2008 U.S. National Health and Nutrition Examination Survey (NHANES). Environ Sci Technol 47: 1137-1147, 2013.

7. Satarug S and Moore MR: Adverse health effects of chronic exposure to low-level cadmium in foodstuffs and cigarette smoke. Environ Health Perspect 112: 1099-1103, 2004.

8. Brama M, Politi L, Santini P, Migliaccio S and Scandurra R: Cadmium-induced apoptosis and necrosis in human osteoblasts: role of caspases and mitogen-activated protein kinases pathways. J Endocrinol Invest 35: 198-208, 2012.

9. Angenard G, Muczynski V, Coffigny $\mathrm{H}$, et al: Cadmium increases human fetal germ cell apoptosis. Environ Health Perspect 118: 331-337, 2010

10. Gordon WL: The absorption, transport and storage of iron. Queens Med Mag (1972) 38: 30-35, 1945.
11. Ganz T: Hepcidin and iron regulation, 10 years later. Blood 117: 4425-4433, 2011.

12. Nemeth E, Tuttle MS, Powelson J, et al: Hepcidin regulates cellular iron efflux by binding to ferroportin and inducing its internalization. Science 306: 2090-2093, 2004.

13. Galy B, Ferring-Appel D, Becker C, et al: Iron regulatory proteins control a mucosal block to intestinal iron absorption. Cell Rep 3: 844-857, 2013

14. Casey JL, Hentze MW, Koeller DM, et al: Iron-responsive elements: regulatory RNA sequences that control mRNA levels and translation. Science 240: 924-928, 1988.

15. Lymboussaki A, Pignatti E, Montosi G, Garuti C, Haile DJ and Pietrangelo A: The role of the iron responsive element in the control of ferroportin1/IREG1/MTP1 gene expression. J Hepatol 39: 710-715, 2003.

16. Drakesmith $\mathrm{H}$ and Prentice AM: Hepcidin and the iron-infection axis. Science 338: 768-772, 2012.

17. Evstatiev R and Gasche C: Iron sensing and signalling. Gut 61: 933-952, 2012

18. Cazzola M: Genetic disorders of iron overload and the novel "ferroportin disease". Haematologica 88: 721-724, 2003.

19. Beutler E, Barton JC, Felitti VJ, et al: Ferroportin 1 (SCL40A1) variant associated with iron overload in African-Americans. Blood Cells Mol Dis 31: 305-309, 2003.

20. Griffiths WJ, Mayr R, McFarlane I, et al: Clinical presentation and molecular pathophysiology of autosomal dominant hemochromatosis caused by a novel ferroportin mutation. Hepatology 51: 788-795, 2010

21. Maeß MB, Wittig B, Cignarella A and Lorkowski S: Reduced PMA enhances the responsiveness of transfected THP-1 macrophages to polarizing stimuli. J Immunol Method 402: 76-81, 2014.

22. Qu G, Zhang C, Yuan L, et al: Quantum dots impair macrophagic morphology and the ability of phagocytosis by inhibiting the Rho-associated kinase signaling. Nanoscale 4: 2239-2244, 2012.

23. Prus E and Fibach E: Flow cytometry measurement of the labile iron pool in human hematopoietic cells. Cytometry A 73: 22-27, 2008.

24. Abboud S and Haile DJ: A novel mammalian iron-regulated protein involved in intracellular iron metabolism. J Biol Chem 275: 19906-19912, 2000.

25. Donovan A, Brownlie A, Zhou Y, et al: Positional cloning of zebrafish ferroportin 1 identifies a conserved vertebrate iron exporter. Nature 403: 776-781, 2000.

26. Donovan A, Lima CA, Pinkus JL, et al: The iron exporter ferroportin/Slc40a1 is essential for iron homeostasis. Cell Metab 1: 191-200, 2005.

27. Weiss G: Iron and immunity: a double-edged sword. Eur J Clin Invest 32 Suppl 1: 70-78, 2002

28. Ganz T: Macrophages and systemic iron homeostasis. J Innate Immun 4: 446-453, 2012.

29. Martelli A and Moulis JM: Zinc and cadmium specifically interfere with RNA-binding activity of human iron regulatory protein 1. J Inorg Biochem 98: 1413-1420, 2004.

30. De Smet H, Blust R and Moens L: Cadmium-binding to transferrin in the plasma of the common carp Cyprinus carpio. Comp Biochem Physiol C Toxicol Pharmacol 128: 45-53, 2001.

31. Brzóska MM and Rogalska J: Protective effect of zinc supplementation against cadmium-induced oxidative stress and the RANK/RANKL/OPG system imbalance in the bone tissue of rats. Toxicol Appl Pharmacol 272: 208-220, 2013.

32. Breuer W, Shvartsman M and Cabantchik ZI: Intracellular labile iron. Int J Biochem Cell Biol 40: 350-354, 2008.

33. Pinnix ZK, Miller LD, Wang W, et al: Ferroportin and iron regulation in breast cancer progression and prognosis. Sci Transl Med 2: 43ra56, 2010.

34. Chen J, Shi YH and Li MY: Changes in transferrin and hepcidin genes expression in the liver of the fish Pseudosciaena crocea following exposure to cadmium. Arch Toxicol 82: 525-530, 2008.

35. Buerge-Weirich D, Hari R, Xue H, Behra P and Sigg L: Adsorption of $\mathrm{Cu}, \mathrm{Cd}$, and $\mathrm{Ni}$ on goethite in the presence of natural groundwater ligands. Environ Sci Technol 36: 328-336, 2002.

36. Gunshin H, Mackenzie B, Berger UV, et al: Cloning and characterization of a mammalian proton-coupled metal-ion transporter. Nature 388: 482-488, 1997.

37. Horiguchi H: Anemia induced by cadmium intoxication. Nihon Eiseigaku Zasshi 62: 888-904, 2007 (In Chinese).

38. Park BY and Chung J: Cadmium increases ferroportin-1 gene expression in $\mathbf{J} 774$ macrophage cells via the production of reactive oxygen species. Nutr Res Pract 3: 192-199, 2009. 